\title{
Advanced Glycation End Products, Diabetes, and Bone Strength
}

\author{
Masahiro Yamamoto $^{1} \cdot$ Toshitsugu Sugimoto $^{1}$
}

Published online: 4 October 2016

(C) The Author(s) 2016. This article is published with open access at Springerlink.com

\begin{abstract}
Diabetic patients have a higher fracture risk than expected by their bone mineral density (BMD). Poor bone quality is the most suitable and explainable cause for the elevated fracture risk in this population. Advanced glycation end products (AGEs), which are diverse compounds generated via a non-enzymatic reaction between reducing sugars and amine residues, physically affect the properties of the bone material, one of a component of bone quality, through their accumulation in the bone collagen fibers. On the other hand, these compounds biologically act as agonists for these receptors for AGEs (RAGE) and suppress bone metabolism. The concentrations of AGEs and endogenous secretory RAGE, which acts as a "decoy receptor" that inhibits the AGEs-RAGE signaling axis, are associated with fracture risk in a BMDindependent manner. AGEs are closely associated with the pathogenesis of this unique clinical manifestation through physical and biological mechanisms in patients with diabetes mellitus.
\end{abstract}

Keywords Fracture $\cdot$ Bone quality $\cdot$ Material properties $\cdot$

Pentosidine $\cdot$ Crosslink $\cdot$ Receptor for advanced glycation end products (RAGE)

This article is part of the Topical Collection on Bone and Diabetes

Masahiro Yamamoto

masa-ya@med.shimane-u.ac.jp

Toshitsugu Sugimoto

sugimoto@med.shimane-u.ac.jp

1 Internal Medicine 1, Shimane University Faculty of Medicine, 89-1 Enya-cho, Izumo, Shimane 693-8501, Japan

\section{Introduction}

Diabetic patients have a higher fracture risk than expected by their bone mineral density (BMD) [1-4]. Bone strength consists of BMD and bone quality [5], suggesting that increased bone fragility in this population is, in part, caused by a deterioration of bone quality. Bone quality, conceptually, is divided into geometrical properties and material properties [6]. The former indicates the morphological characteristics of bone. Some studies indicate that aggravation of the structural properties assessed by high-resolution peripheral quantitative computed tomography (HR-pQCT) and trabecular bone score (TBS) is involved in bone fragility [7-9]. The material properties of bone, another component of bone quality, are regulated by tissue turnover, cellular activity, and oxidative stress and glycation [10]. Advanced glycation end products (AGEs) are diverse compounds that are generated via a non-enzymatic reaction between reducing sugars and the amine residues on proteins, lipids, and nucleic acids. Growing evidence of fracture risk in patients with diabetes mellitus indicates the crucial roles of AGEs in aggravating bone fragility, as in the cases of the progression of classical diabetic complications [11]. This review focuses on the material properties and summarizes the association between AGEs and bone fragility in patients with diabetes.

\section{Bone Mineral Density in Diabetic Patients}

The measurement of BMD is an established method for assessing bone strength. An association between decreased $\mathrm{BMD}$, as measured by dual-energy X-ray absorptiometry (DXA), and the fracture rate was observed in postmenopausal women with osteoporosis. In 1991, osteoporosis was defined 
as "a disease that is characterized by low bone mass, microarchitectural deterioration of bone tissue leading to enhanced bone fragility, and consequent increase in fracture risk" [12], and the diagnostic criteria for osteoporosis, which were primarily based on BMD, were established. In contrast, there was less information on the BMD values of diabetic patients. Diabetes mellitus is classified into two major types: type 1 diabetes mellitus (T1DM), which is caused by a loss of the ability to secrete insulin that possesses an anabolic action on bone, and type 2 diabetes mellitus (T2DM), which develops in the presence of underlying insulin resistance. In T1DM, BMD measured in the femoral neck or the lumbar vertebrae has been reported to be significantly lower than the respective value in age- and body mass index-matched non-diabetic subjects $[13,14]$; these findings were consistently confirmed in other reports $[15,16]$. A meta-analysis published in 2007 showed that the BMD $z$ scores (the ageadjusted BMD) of hip and spine in T1DM patients were lower than the scores in non-diabetic participants [1]. In contrast, the BMD values at these sites in T2DM patients were inconsistent; early reports with a small number of patients showed that the BMD values were lower than, equivalent to, or higher than the values in the control groups [17-20]. However, successive reports from large-scale studies indicated that the BMD values in these subjects were significantly higher than the values in non-diabetic populations [21, 22]. The meta-analysis of these studies revealed that the BMD $z$ scores in T2DM patients were higher than the scores in the non-diabetic population, unlike the T1DM patients [1].

\section{The Risk of Fracture in Diabetic Patients}

The relationship between the presence of diabetes and risk of fracture has been investigated by the clinical type of diabetes. In patients with T1DM, the risk of hip fractures has been reported to be significantly higher in female patients compared with non-diabetic subjects after adjusting for confounding factors [23, 24]. Two meta-analyses confirmed the consistent relationship between the presence of diabetes and risk of fracture [1, 2]. In contrast, the findings obtained from the patients with T2DM have confused us for a long time. Some reports indicated that the risk of hip fractures is increased in T2DM. However, others showed the opposite results. Two meta-analyses concluded that the risk of hip fracture in subjects with T2DM is significantly higher than the risk in non-diabetic subjects, although their BMD was higher than the control group [1, 2]. Taken together, these findings suggest that diabetes mellitus is an underlying disease that causes secondary osteoporosis because the risk of fracture is increased in diabetic patients, irrespective of their diabetic clinical type.

\section{AGEs and Bone Fragility in Diabetes}

(a) Physical effects of AGEs on bone fragility

AGE is a generic name for the various products formed from Amadori compounds by spontaneous dehydration, transposition, condensation, and oxidation reactions. Amadori compounds are generated from a non-enzymatic condensation reaction known as the Maillard reaction between amino groups and carbonyl groups, such as amino acid and reducing sugars, respectively. Thus, proteins with long half-lives, such as collagen, have more opportunities for their lateral chains to become glycated. Type I collagen is considered a major determinant factor for the material properties of bone strength because it is a prominent protein component of bone matrix. Collagen fibers are built from collagen molecules that are connected to each other through crosslinking at genetically determined site by specific enzymes, such as lysine hydroxylase and lysyl oxidase [25, 26]. Enzymatic crosslinking contributes to the improvements in tissue strength by changing the material properties of bone, such as increasing collagen stiffness [27, 28].

On the other hand, it is possible that non-enzymatic crosslinking of collagen occurs as a ubiquitous glycation process. Pentosidine (PEN) and carboxymethyl lysine (CML) are well-recognized AGEs that possess lysine or arginine residues. Because these residues in collagen fibers are used as precursor substances for the formation of these AGEs [29], PEN and CML are non-enzymatically produced in collagen fibers as crosslinked and noncrosslinked types of AGEs, respectively. In contrast to the formation of enzymatic crosslinks, an increase in non-enzymatic crosslinking by AGEs, including PEN, deteriorates bone strength. Several ex vivo studies obtained from human samples indicate that the PEN content in cancellous bone specimens from the tibia, cortical bone samples from the femoral mid-shaft and tibial mid-shaft, and trabecular bone particles from the vertebrae are inversely associated with ultimate strain, ultimate stress, and fracture toughness [30-33], with the exception of one report [34]. Indeed, the bone PEN content obtained from non-diabetic patients with hip fracture is significantly increased compared with non-diabetic patients without fracture in the clinical setting $[35,36]$, suggesting that an increase in the non-enzymatic crosslinked type of AGEs in collagen fibers is a well-established cause of the deterioration of bone strength. The pre-yield mechanical change in bone tissue is dominantly determined by its mineral composition; in contrast, the post-yield mechanical feature is defined by the organic matrix [37]. Indeed, several studies of non-diabetic subjects revealed that increased AGEs crosslinking was associated with reduced post-yield properties and toughness [31, 32, 38-41]. 
These findings suggest that AGEs potentially disturb bone strength partially through the physical influence of the excess collagen crosslinking.

The physical effects of AGEs on bone fragility are more evident in diabetic patients than in non-diabetic patients. Saito et al. showed that the bone content of PEN, a non-enzymatic crosslinked type of AGE, is significantly increased in spontaneously diabetic rats just before the onset of diabetes and that bone strength measured by the three-point bending fixture test in the diabetic group was significantly decreased compared to the control group [42]. Specimens obtained by iliac crest bone biopsy in patients with T1DM showed that the bone PEN content in subjects with fracture was significantly increased compared with subjects without fracture $[43 \cdot \bullet]$. PEN is a potent surrogate marker for total AGEs production because the bone PEN content reflects the total amount of AGEs in bone [44]. Accumulation of PEN in skin and bone exponentially increase with age $[45,46]$, and these amounts may be closely related to each other. The material strength of the bones in patients with T2DM, as confirmed by microindentation, was inferior to the non-diabetic subjects and was significantly and inversely associated with the levels of skin autofluorescence [47], indicating that the bone accumulation of AGEs aggravates the material properties of bone. Cross-sectional and prospective clinical studies showed that increased serum and urinary PEN concentrations were related to an increased risk of fractures in patients with type 1 and type 2 diabetes mellitus [48-50, 51•] (Table 1). These associations are independent of BMD. Therefore, the bone fragility of patients with diabetes, which cannot be assessed by BMD, is well explained by the poor material properties of bone caused by an increase in the levels of non-enzymatic crosslinked type AGEs, such as PEN.

A prospective clinical study of non-diabetic subjects showed that the circulating levels of CML are associated with hip fracture risk [52•]. Recently, the bone content of CML, a non-enzymatic non-crosslinked type of AGE, in a mouse model of type 1 diabetes was significantly increased compared with the control mice and was significantly and inversely correlated with macroscopic bone toughness, similar to PEN [53]. There is no in vitro study that revealed a significant association between an increase in the bone content of CML and a reduction of bone strength. CML appears to be the dominant AGE component. Therefore, the amount of CML may reflect the amount of PEN.

\section{(b) Biological effects of AGEs on bone fragility}

AGEs also have biological effects on bone metabolism. The receptor for AGEs (RAGE), which is presented on the
Table 1 The association between serum or urinary pentosidine levels and fractures in patients with diabetes

\begin{tabular}{ll}
\hline & OR $(95 \% \mathrm{CI})$ \\
\hline Vertebral fractures & \\
Yamamoto [48] & $2.50(1.09-5.73)^{*}$ \\
Yamamoto [49] & $1.82(1.05-3.15)^{*}$ \\
Schwartz [50] & $5.93(2.08-16.9)^{* *}$ \\
Clinical fractures & \\
Schwartz [50] & $1.42(1.10-1.83)^{* *}$ \\
Osteoporotic fractures & \\
Neumann [51•] & $1.02(1.00-1.03)^{* *}$ \\
\hline
\end{tabular}

Data are expressed as odds ratio of fracture after adjustment for multiple covariates per 1 unit increase in pentosidine. References [48-50], per standard deviation increase; ref. [32], per $1 \mathrm{pmol} / \mathrm{mL}$ increase.

$* P<0.05 ; * * P<0.01$

surface of specific cells, recognizes AGEs as ligands [54] and is involved in the progression of diabetic complications, such as diabetic nephropathy [55]. AGEs significantly inhibit osteoblast proliferation and induce osteoblast apoptosis [56-59] and IGF-1 secretion [60]. Hyperglycemia and AGEs suppress osteoblastic differentiation and mineralization, accompanied by enhanced RAGE expression [61-63]. A reactive oxygen species (ROS) inhibitor and autophagy inducer prevent AGE-induced osteoblast apoptosis, indicating that the elevation of oxidative stress and inhibition of autophagy are involved in this event [64]. Recently, a rat model with an autograft implant containing AGEs showed that the mineral apposition rate (MAR), mineralized surface per bone surface (MS/BS), and bone formation rate (BFR) were significantly reduced, suggesting that the AGEs that accumulated in the matrix are also involved in the reduced bone formation in vivo [65]. These observations suggest that the AGE-RAGE axis plays an important role in the bone formation process. On the other hand, AGEs decreased osteoclast-induced bone resorption and the osteoclastic differentiation process [66]. AGEs increased the expression of the sclerostin protein, an antagonist of bone formation, and decreased the expression of the RANKL protein, an agonist of bone resorption, in osteocyte-like MLO-Y4-A2 cells [67]. In addition, parathyroid hormone (PTH) secretion is inhibited by AGEs and high glucose concentrations [68, 69]. These findings suggested that the pathogenesis of suppressed bone turnover, one of the characteristics of bone metabolic disorders in diabetes, is partially explained by increased AGE levels. Indeed, low bone turnover and concomitant low PTH levels are observed in patients with T2DM [70, 71] and are associated with an elevated risk of vertebral fracture [70]. This finding is independent of BMD, suggesting 
The association between serum levels of pentosidine as well as endogenous secretory

receptor for advanced glycation endproducts (esRAGE) and vertebral fractures in patients with Type2 diabetes mellitus

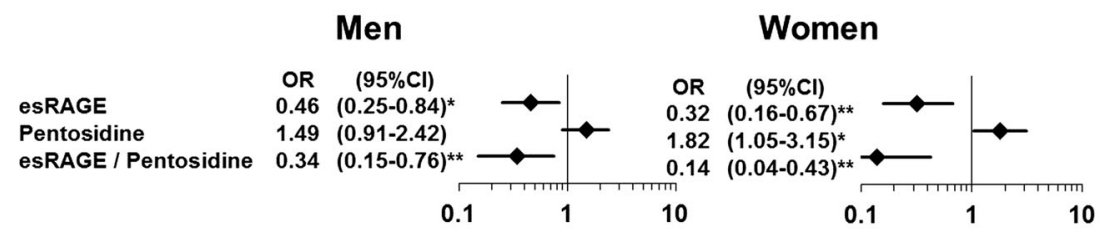

Data are expressedas odds ratio of vertebral fracture adjusting for age, body mass index,

$\mathrm{HbA} 1 \mathrm{c}$, creatine, duration of diabetes and spine bone mineral density per standard deviation

increase in each factor.

$\mathrm{OR}$, odds ratio; $\mathrm{Cl}$, confidence interval; esRAGE, endogenous secretory receptor for

advanced glycation end-products
$\star, P<0.05 ; * \star$

Fig. 1 The association between the serum levels of pentosidine as well as endogenous secretory receptor for advanced glycation end products (esRAGE) and vertebral fractures in patients with type 2 diabetes mellitus. The data are expressed as odds ratios of vertebral fracture after adjusting for age, body mass index, HbAlc levels, creatine levels, duration of diabetes, and spine bone mineral density per standard deviation increase in each factor. $O R$, odds ratio; $C I$, confidence interval; esRAGE, endogenous secretory receptor for advanced glycation end products. $* P<0.05 ; * * P<0.01$. Adapted from ref. [49]

diabetes may be rescued by improving the bone formation or material properties of bone. In the subanalysis of the MORE study, which examined the preventive effect of raloxifene on vertebral fracture in postmenopausal osteoporotic women, the risk of vertebral fracture after the treatment in the subgroup with diabetes was lower than that in the non-diabetic subgroup [73]. When a nondiabetic animal with elevated PEN induced by experimental diet was treated with raloxifene, bone strength recovered, presumably by decreasing the bone PEN content [74]. Therefore, raloxifene administration to diabetic patients is expected to improve the material properties of the bone matrix and prevent fractures. On the other hand, the risk of fracture in diabetic patients also increases as the BMD decreases [4]; therefore, agents that are capable of increasing BMD may be useful in preventing fractures. Teriparatide, the only current agent used to promote bone formation, decreased the bone PEN content and increased BMD in a non-diabetic animal model [75]. Teriparatide may be useful as a treatment for osteoporosis in diabetic patients because it could improve the bone matrix quality by reversing the impaired bone turnover in diabetic patients. A recent study revealed that the reduction in nonvertebral fracture incidence, increase in BMD, and decrease in back pain by treatment with teriparatide were similar in T2DM and non-diabetic patients [76]. On the other hand, bisphosphonates, which suppress bone resorption, increase BMD in T2DM patients whose bone turnover was decreased to similar degree compared to nondiabetic subjects [77], suggesting that these agents may possess particular advantages in preventing fracture in

the diabetic patients with decreased BMD.
A few clinical studies showed that some anti-osteoporosis agent drugs potentially prevent fractures in diabetic patients. When considering the pathological state of osteoporosis in diabetic patients, bone fragility in patients with 


\section{Conclusions}

The bone fragility in patients with diabetes mellitus is predominantly caused by poor bone quality because BMD is not always a useful estimate of the bone fragility of diabetic patients. AGEs are closely associated with the pathogenesis of this unique clinical manifestation through physical and biological effects on the deterioration of the material properties of bone. Further studies that clarify the etiologic mechanisms of diabetic bone fragility would provide unique diagnostic criteria and treatment strategies for this specific form of osteoporosis.

\section{Compliance with Ethical Standards}

Conflict of Interest Masahiro Yamamoto and Toshitsugu Sugimoto declare no conflict of interest.

Human and Animal Rights and Informed Consent This article does not contain any studies with human or animal subjects performed by any of the authors.

Open Access This article is distributed under the terms of the Creative Commons Attribution 4.0 International License (http:// creativecommons.org/licenses/by/4.0/), which permits unrestricted use, distribution, and reproduction in any medium, provided you give appropriate credit to the original author(s) and the source, provide a link to the Creative Commons license, and indicate if changes were made.

\section{References}

Papers of particular interest, published recently, have been highlighted as:

- Of importance

-. Of major importance

1. Vestergaard P. Discrepancies in bone mineral density and fracture risk in patients with type 1 and type 2 diabetes - a meta-analysis. Osteoporos Int. 2007;18(4):427-44.

2. Janghorbani M, Van Dam RM, Willett WC, Hu FB. Systematic review of type 1 and type 2 diabetes mellitus and risk of fracture. Am J Epidemiol. 2007;166(5):495-505.

3. Yamamoto M, Yamaguchi T, Yamauchi M, Kaji H, Sugimoto T. Diabetic patients have an increased risk of vertebral fractures independent of BMD or diabetic complications. J Bone Miner Res. 2009;24(4):702-9.

4. Schwartz AV, Vittinghoff E, Bauer DC, Hillier TA, Strotmeyer ES, Ensrud KE, et al. Association of BMD and FRAX score with risk of fracture in older adults with type 2 diabetes. JAMA. 2011;305(21): 2184-92.

5. Anonymous. Osteoporosis prevention, diagnosis, and therapy. JAMA. 2001;285(6):785-95.

6. Martin RM, Correa PH. Bone quality and osteoporosis therapy. Arq Bras Endocrinol Metabol. 2010;54(2):186-99.

7. Burghardt AJ, Issever AS, Schwartz AV, Davis KA, Masharani U, Majumdar S, et al. High-resolution peripheral quantitative computed tomographic imaging of cortical and trabecular bone microarchitecture in patients with type 2 diabetes mellitus. J Clin Endocrinol Metab. 2010;95(11):5045-55.

8. Patsch JM, Burghardt AJ, Yap SP, Baum T, Schwartz AV, Joseph $\mathrm{GB}$, et al. Increased cortical porosity in type 2 diabetic postmenopausal women with fragility fractures. J Bone Miner Res. 2013;28(2):313-24.

9. Leslie WD, Aubry-Rozier B, Lamy O, Hans D. Manitoba Bone Density P: TBS (trabecular bone score) and diabetes-related fracture risk. J Clin Endocrinol Metab. 2013;98(2):602-9.

10. Burr DB. Bone quality: understanding what matters. J Musculoskelet Neuronal Interact. 2004;4(2):184-6.

11. Goh SY, Cooper ME. Clinical review: the role of advanced glycation end products in progression and complications of diabetes. J Clin Endocrinol Metab. 2008;93(4):1143-52.

12. Anonymous. Consensus development conference: prophylaxis and treatment of osteoporosis. Am J Med. 1991;90(1):107-10.

13. Tuominen JT, Impivaara O, Puukka P, Ronnemaa T. Bone mineral density in patients with type 1 and type 2 diabetes. Diabetes Care. 1999;22(7):1196-200.

14. Kemink SA, Hermus AR, Swinkels LM, Lutterman JA, Smals AG. Osteopenia in insulin-dependent diabetes mellitus; prevalence and aspects of pathophysiology. J Endocrinol Invest. 2000;23(5):295303.

15. Campos Pastor MM, Lopez-Ibarra PJ, Escobar-Jimenez F, Serrano Pardo MD, Garcia-Cervigon AG. Intensive insulin therapy and bone mineral density in type 1 diabetes mellitus: a prospective study. Osteoporos Int. 2000;11(5):455-9.

16. Lopez-Ibarra PJ, Pastor MM, Escobar-Jimenez F, Pardo MD, Gonzalez AG, Luna JD, et al. Bone mineral density at time of clinical diagnosis of adult-onset type 1 diabetes mellitus. Endocr Pract. 2001;7(5):346-51.

17. Isaia G, Bodrato L, Carlevatto V, Mussetta M, Salamano G, Molinatti GM. Osteoporosis in type II diabetes. Acta Diabetol Lat. 1987;24(4):305-10.

18. Wakasugi M, Wakao R, Tawata M, Gan N, Koizumi K, Onaya T. Bone mineral density measured by dual energy X-ray absorptiometry in patients with non-insulin-dependent diabetes mellitus. Bone. 1993;14(1):29-33.

19. Barrett-Connor E, Holbrook TL. Sex differences in osteoporosis in older adults with non-insulin-dependent diabetes mellitus. JAMA. 1992;268(23):3333-7.

20. Weinstock RS, Goland RS, Shane E, Clemens TL, Lindsay R, Bilezikian JP. Bone mineral density in women with type II diabetes mellitus. J Bone Miner Res. 1989;4(1):97-101.

21. van Daele PL, Stolk RP, Burger H, Algra D, Grobbee DE, Hofman A, et al. Bone density in non-insulin-dependent diabetes mellitus. The Rotterdam Study. Ann Intern Med. 1995;122(6):409-14.

22. Schwartz AV, Sellmeyer DE, Ensrud KE, Cauley JA, Tabor HK, Schreiner PJ, et al. Older women with diabetes have an increased risk of fracture: a prospective study. J Clin Endocrinol Metab. 2001;86(1):32-8.

23. Forsen L, Meyer HE, Midthjell K, Edna TH. Diabetes mellitus and the incidence of hip fracture: results from the Nord-Trondelag Health Survey. Diabetologia. 1999;42(8):920-5.

24. Nicodemus KK, Folsom AR. Type 1 and type 2 diabetes and incident hip fractures in postmenopausal women. Diabetes Care. 2001;24(7):1192-7.

25. Eyre DR, Paz MA, Gallop PM. Cross-linking in collagen and elastin. Annu Rev Biochem. 1984;53:717-48.

26. Uzawa K, Grzesik WJ, Nishiura T, Kuznetsov SA, Robey PG, Brenner DA, et al. Differential expression of human lysyl hydroxylase genes, lysine hydroxylation, and cross-linking of type I collagen during osteoblastic differentiation in vitro. J Bone Miner Res. 1999;14(8):1272-80. 
27. Bailey AJ, Paul RG, Knott L. Mechanisms of maturation and ageing of collagen. Mech Ageing Dev. 1998;106(1-2):1-56.

28. Depalle B, Qin Z, Shefelbine SJ, Buehler MJ. Influence of crosslink structure, density and mechanical properties in the mesoscale deformation mechanisms of collagen fibrils. J Mech Behav Biomed Mater. 2015;52:1-13.

29. Monnier VM, Sell DR, Nagaraj RH, Miyata S, Grandhee S, Odetti $\mathrm{P}$, et al. Maillard reaction-mediated molecular damage to extracellular matrix and other tissue proteins in diabetes, aging, and uremia. Diabetes. 1992;41 Suppl 2:36-41.

30. Karim L, Vashishth D. Heterogeneous glycation of cancellous bone and its association with bone quality and fragility. PLoS One. 2012;7(4):e35047.

31. Wang X, Shen X, Li X, Agrawal CM. Age-related changes in the collagen network and toughness of bone. Bone. 2002;31(1):1-7.

32. Nyman JS, Roy A, Tyler JH, Acuna RL, Gayle HJ, Wang X. Agerelated factors affecting the postyield energy dissipation of human cortical bone. J Orthop Res. 2007;25(5):646-55.

33. Hernandez CJ, Tang SY, Baumbach BM, Hwu PB, Sakkee AN, van der Ham F, et al. Trabecular microfracture and the influence of pyridinium and non-enzymatic glycation-mediated collagen crosslinks. Bone. 2005;37(6):825-32.

34. Follet H, Viguet-Carrin S, Burt-Pichat B, Depalle B, Bala Y, Gineyts E, et al. Effects of preexisting microdamage, collagen cross-links, degree of mineralization, age, and architecture on compressive mechanical properties of elderly human vertebral trabecular bone. J Orthop Res. 2011;29(4):481-8.

35. Saito M, Fujii K, Soshi S, Tanaka T. Reductions in degree of mineralization and enzymatic collagen cross-links and increases in glycation-induced pentosidine in the femoral neck cortex in cases of femoral neck fracture. Osteoporos Int. 2006;17(7):986-95.

36. Saito M, Fujii K, Marumo K. Degree of mineralizationrelated collagen crosslinking in the femoral neck cancellous bone in cases of hip fracture and controls. Calcif Tissue Int. 2006;79(3):160-8.

37. Burstein AH, Zika JM, Heiple KG, Klein L. Contribution of collagen and mineral to the elastic-plastic properties of bone. J Bone Joint Surg Am. 1975;57(7):956-61.

38. Nyman JS, Roy A, Acuna RL, Gayle HJ, Reyes MJ, Tyler JH, et al. Age-related effect on the concentration of collagen crosslinks in human osteonal and interstitial bone tissue. Bone. 2006;39(6): 1210-7.

39. Viguet-Carrin S, Roux JP, Arlot ME, Merabet Z, Leeming DJ, Byrjalsen I, et al. Contribution of the advanced glycation end product pentosidine and of maturation of type I collagen to compressive biomechanical properties of human lumbar vertebrae. Bone. 2006;39(5):1073-9.

40. Saito M, Mori S, Mashiba T, Komatsubara S, Marumo K. Collagen maturity, glycation induced-pentosidine, and mineralization are increased following 3-year treatment with incadronate in dogs. Osteoporos Int. 2008;19(9):1343-54.

41. Tang SY, Allen MR, Phipps R, Burr DB, Vashishth D. Changes in non-enzymatic glycation and its association with altered mechanical properties following 1-year treatment with risedronate or alendronate. Osteoporos Int. 2009;20(6):887-94.

42. Saito M, Fujii K, Mori Y, Marumo K. Role of collagen enzymatic and glycation induced cross-links as a determinant of bone quality in spontaneously diabetic WBN/Kob rats. Osteoporos Int. 2006;17(10):1514-23.

43.• Farlay D, Armas LA, Gineyts E, Akhter MP, Recker RR, Boivin G. Nonenzymatic glycation and degree of mineralization are higher in bone from fractured patients with type 1 diabetes mellitus. J Bone Miner Res. 2016;31(1):190-5. For the first time, this report showed that the bone pentosidine content was significantly associated with the risk of fracture in humans.
44. Dong XN, Qin A, Xu J, Wang X. In situ accumulation of advanced glycation endproducts (AGEs) in bone matrix and its correlation with osteoclastic bone resorption. Bone. 2011;49(2):174-83.

45. Odetti P, Rossi S, Monacelli F, Poggi A, Cirnigliaro M, Federici M, et al. Advanced glycation end products and bone loss during aging. Ann N Y Acad Sci. 2005;1043:710-7.

46. Sell DR, Monnier VM. Structure elucidation of a senescence crosslink from human extracellular matrix. Implication of pentoses in the aging process. J Biol Chem. 1989;264(36):21597-602.

47. Furst JR, Bandeira LC, Fan WW, Agarwal S, Nishiyama KK, McMahon DJ, et al. Advanced glycation endproducts and bone material strength in type 2 diabetes. J Clin Endocrinol Metab. 2016;101(6):2502-10.

48. Yamamoto M, Yamaguchi T, Yamauchi M, Yano S, Sugimoto T. Serum pentosidine levels are positively associated with the presence of vertebral fractures in postmenopausal women with type 2 diabetes. J Clin Endocrinol Metab. 2008;93(3):1013-9.

49. Yamamoto M, Yamaguchi T, Yamauchi M, Sugimoto T. Low serum level of the endogenous secretory receptor for advanced glycation end products (esRAGE) is a risk factor for prevalent vertebral fractures independent of bone mineral density in patients with type 2 diabetes. Diabetes Care. 2009;32(12):2263-8.

50. Schwartz AV, Garnero P, Hillier TA, Sellmeyer DE, Strotmeyer ES, Feingold KR, et al. Pentosidine and increased fracture risk in older adults with type 2 diabetes. J Clin Endocrinol Metab. 2009;94(7): 2380-6.

51. Neumann T, Lodes S, Kastner B, Franke S, Kiehntopf M, Lehmann $\mathrm{T}$, et al. High serum pentosidine but not esRAGE is associated with prevalent fractures in type 1 diabetes independent of bone mineral density and glycaemic control. Osteoporos Int. 2014;25(5):152733. This study found that the serum pentosidine levels were significantly and positively associated with the risk of fracture in patients with type 1 diabetes mellitus.

52. Barzilay JI, Buzkova P, Zieman SJ, Kizer JR, Djousse L, Ix JH, et al. Circulating levels of carboxy-methyl-lysine (CML) are associated with hip fracture risk: the Cardiovascular Health Study. J Bone Miner Res. 2014;29(5):1061-6. This study is the only report showing that the serum carboxy-methyl-lysine levels were significantly and positively associated with the risk of hip fracture.

53. Rubin MR, Paschalis EP, Poundarik A, Sroga GE, McMahon DJ, Gamsjaeger $\mathrm{S}$, et al. Advanced glycation endproducts and bone material properties in type 1 diabetic mice. PLoS One. 2016;11(5):e0154700.

54. Kislinger T, Fu C, Huber B, Qu W, Taguchi A, Du Yan S, et al. $\mathrm{N}$ (epsilon)-(carboxymethyl)lysine adducts of proteins are ligands for receptor for advanced glycation end products that activate cell signaling pathways and modulate gene expression. J Biol Chem. 1999;274(44):31740-9.

55. Yamamoto Y, Kato I, Doi T, Yonekura H, Ohashi S, Takeuchi M, et al. Development and prevention of advanced diabetic nephropathy in RAGE-overexpressing mice. J Clin Invest. 2001;108(2):2618.

56. Alikhani M, Alikhani Z, Boyd C, MacLellan CM, Raptis M, Liu R, et al. Advanced glycation end products stimulate osteoblast apoptosis via the MAP kinase and cytosolic apoptotic pathways. Bone. 2007;40(2):345-53

57. Mercer N, Ahmed H, Etcheverry SB, Vasta GR, Cortizo AM. Regulation of advanced glycation end product (AGE) receptors and apoptosis by AGEs in osteoblast-like cells. Mol Cell Biochem. 2007;306(1-2):87-94.

58. Franke S, Ruster C, Pester J, Hofmann G, Oelzner P, Wolf G. Advanced glycation end products affect growth and function of osteoblasts. Clin Exp Rheumatol. 2011;29(4):650-60.

59. Kume S, Kato S, Yamagishi S, Inagaki Y, Ueda S, Arima N, et al. Advanced glycation end-products attenuate human mesenchymal 
stem cells and prevent cognate differentiation into adipose tissue, cartilage, and bone. J Bone Miner Res. 2005;20(9):1647-58.

60. McCarthy AD, Etcheverry SB, Cortizo AM. Effect of advanced glycation endproducts on the secretion of insulin-like growth factor-I and its binding proteins: role in osteoblast development. Acta Diabetol. 2001;38(3):113-22.

61. Ogawa N, Yamaguchi T, Yano S, Yamauchi M, Yamamoto M, Sugimoto T. The combination of high glucose and advanced glycation end-products (AGEs) inhibits the mineralization of osteoblastic MC3T3-E1 cells through glucose-induced increase in the receptor for AGEs. Horm Metab Res. 2007;39(12):871-5.

62. Okazaki K, Yamaguchi T, Tanaka K, Notsu M, Ogawa N, Yano S, et al. Advanced glycation end products (AGEs), but not high glucose, inhibit the osteoblastic differentiation of mouse stromal ST2 cells through the suppression of osterix expression, and inhibit cell growth and increasing cell apoptosis. Calcif Tissue Int. 2012;91(4): 286-96.

63. Notsu M, Yamaguchi T, Okazaki K, Tanaka K, Ogawa N, Kanazawa I, et al. Advanced glycation end product 3 (AGE3) suppresses the mineralization of mouse stromal ST2 cells and human mesenchymal stem cells by increasing TGF-beta expression and secretion. Endocrinology. 2014;155(7):2402-10.

64. Yang L, Meng H, Yang M. Autophagy protects osteoblasts from advanced glycation end products-induced apoptosis through intracellular reactive oxygen species. J Mol Endocrinol. 2016;56(4): 291-300.

65. Yang X, Mostafa AJ, Appleford M, Sun LW, Wang X. Bone formation is affected by matrix advanced glycation end products (AGEs) in vivo. Calcif Tissue Int. 2016.

66. Valcourt U, Merle B, Gineyts E, Viguet-Carrin S, Delmas PD, Garnero P. Non-enzymatic glycation of bone collagen modifies osteoclastic activity and differentiation. J Biol Chem. 2007;282(8):5691-703.

67. Tanaka K, Yamaguchi T, Kanazawa I, Sugimoto T. Effects of high glucose and advanced glycation end products on the expressions of sclerostin and RANKL as well as apoptosis in osteocyte-like MLOY4-A2 cells. Biochem Biophys Res Commun. 2015;461(2):193-9.

68. Yamamoto T, Ozono K, Miyauchi A, Kasayama S, Kojima Y, Shima M, et al. Role of advanced glycation end products in adynamic bone disease in patients with diabetic nephropathy. Am J Kidney Dis. 2001;38(4 Suppl 1):S161-4.

69. Sugimoto T, Ritter C, Morrissey J, Hayes C, Slatopolsky E. Effects of high concentrations of glucose on PTH secretion in parathyroid cells. Kidney Int. 1990;37(6):1522-7.

70. Yamamoto M, Yamaguchi T, Nawata K, Yamauchi M, Sugimoto T. Decreased PTH levels accompanied by low bone formation are associated with vertebral fractures in postmenopausal women with type 2 diabetes. J Clin Endocrinol Metab. 2012;97(4):1277-84.

71. Dobnig H, Piswanger-Solkner JC, Roth M, Obermayer-Pietsch B, Tiran A, Strele A, et al. Type 2 diabetes mellitus in nursing home patients: effects on bone turnover, bone mass, and fracture risk. J Clin Endocrinol Metab. 2006;91(9):3355-63.

72. Yonekura H, Yamamoto Y, Sakurai S, Petrova RG, Abedin MJ, Li $\mathrm{H}$, et al. Novel splice variants of the receptor for advanced glycation end-products expressed in human vascular endothelial cells and pericytes, and their putative roles in diabetes-induced vascular injury. Biochem J. 2003;370(Pt 3):1097-109.

73. Johnell O, Kanis JA, Black DM, Balogh A, Poor G, Sarkar S, et al. Associations between baseline risk factors and vertebral fracture risk in the Multiple Outcomes of Raloxifene Evaluation (MORE) Study. J Bone Miner Res. 2004;19(5):764-72.

74. Saito M, Marumo K, Soshi S, Kida Y, Ushiku C, Shinohara A. Raloxifene ameliorates detrimental enzymatic and nonenzymatic collagen cross-links and bone strength in rabbits with hyperhomocysteinemia. Osteoporos Int. 2010;21(4):655-66.

75. Saito M, Marumo K, Kida Y, Ushiku C, Kato S, Takao-Kawabata $\mathrm{R}$, et al. Changes in the contents of enzymatic immature, mature, and non-enzymatic senescent cross-links of collagen after onceweekly treatment with human parathyroid hormone (1-34) for 18 months contribute to improvement of bone strength in ovariectomized monkeys. Osteoporos Int. 2011;22(8):2373-83.

76. Schwartz AV, Pavo I, Alam J, Disch DP, Schuster D, Harris JM, et al. Teriparatide in patients with osteoporosis and type 2 diabetes. Bone. 2016;91:152-8.

77. Keegan TH, Schwartz AV, Bauer DC, Sellmeyer DE, Kelsey JL. Effect of alendronate on bone mineral density and biochemical markers of bone turnover in type 2 diabetic women: the fracture intervention trial. Diabetes Care. 2004;27(7):1547-53. 